\title{
ACCEPTANCE OF DISABILITY OF SUDDEN ONSET IN PARAPLEGIA
}

\author{
By W. G. Kerr, M.B., F.R.C.S.E. and M. A. Thompson, A.I.M.S.W. \\ Paraplegic Unit, Edenhall Hospital, Musselburgh, Midlothian, Scotland
}

\begin{abstract}
SCOPE
ThIs survey is based on the care of I8I cases of recent acute paraplegia admitted to Edenhall Hospital during the ten years from I.I.6I to 3I.I2.70.
\end{abstract}

\section{DEFINITION}

Acceptance or rejection of disability are commonly used terms but they are open to the objection that they give rise to the impression of a clear-cut voluntary exercise of free will. We feel that mental adjustment would be a better term as this also suggests that the process is a gradual one and it can also take into account the state of mind existing before the disability.

It will be generally agreed that while roo per cent. acceptance is impossible a large number of patients make a good or excellent adjustment. This cannot be graded objectively and may take a long time to complete but an intimate knowledge of the patients has resulted in a grading, from failure to excellent adjustment for each patient, on which the authors were in virtually complete agreement.

\section{GENERAL PATTERN}

The newly disabled patient has two tasks in front of him-he must not only endeavour to overcome his physical disability but he must also move from a position of total dependence on the hospital staff back to a position of self-esteem and to a new position in the home, where possible, and in interpersonal relationships.

He has, in other words, lost his identity and must find it again and he will need all the help and support that he can get in the process.

We sometimes tend to ignore the similarity between the general pattern and the stages each individual goes through, from total dependence in infancy through childhood and adolescence to independence and finally to a more mature interdependence. In a unit where morale is high the staff is unconsciously carrying out the role of a good parent-in command and giving security and yet inevitably restrictive, which is bound, at some stage, to give rise to resentment and aggressive behaviour, that is 'adolescent' or 'childish' behaviour. These tensions can be lessened if the grosser inequalities between people can be diminished, but the child, or patient, will not be helped to full reintegration of his personality if he is allowed to have it all his own way. On the other hand the infant who is cowed and submissive on the way to childhood, or the child on the way through adolescence will never mature fully and some degree of rebellion must be accepted and worked through (Storr, I960). 
Just as the body automatically maintains a physical equilibrium so the mind is automatically seeking equilibrium and human relationships are an essential part of this process (Storr, I960). Physiotherapists, occupational therapists and others all play their part-to carry the analogy further, they have the same role in reintegration as the schoolteacher has on the developing child.

\section{STAGES OF ADJUSTMENT}

Initial Mental Shock, Fear and Anxiety. There were I 29 of our patients admitted within three months of onset, 47 between three months and one year and five between one and two years. Many were therefore seen at an early stage and many were still suffering from doubts and anxieties either because they had never been told their prognosis or because they had misunderstood what they had been told.

Uncertainty about the future gives rise to worry and anxiety and postponement of discussion does nothing to relieve the anxiety and does nothing to diminish grief, although it may lead to its suppression which gives rise to difficulties in adjustment later. We suspect the patient who is transferred to our unit with a bright and cheerful, but almost certainly false, exterior.

Within a few hours of admission the prognosis is discussed as honestly and fairly as possible by one of us (W. G. K.) both with the patient, and, if possible, with the nearest relatives. This is followed up by the presentation of Dr. Walsh's excellent book, Understanding Paraplegia (1964), and by active support by the medical social worker, the other author of this paper.

All other members of the staff, relatives and friends can then discuss problems and carry out treatment free of inhibitions.

Grief and Mourning. This stage is inevitable and, as has already been emphasised must be anticipated and supported rather than repressed. There will be dispair at the loss of physical ability, sexual potency and their former place in society. The first two questions usually asked are 'Will I be able to walk again?' and 'Will I be able to work again?', the latter question emphasising the previous social position. The third question is there but suppressed: 'Will I be able to have sex again?' Knowing that the question is there the patient is told that the answer will vary from individual to individual and that full discussion will be possible once he is up in a wheelchair.

In a few, and fortunately a very few cases the stage of grief is never passed. The patient sees no hope for the future and turns his face to the wall, but even with these patients constant help and encouragement may eventually lead to a better adjustment.

Aggression or Rebellion. We have emphasised that this is an inevitable stage in the progress to maturity. Our patients must not be regarded as a flock of sheep (Forman, 1971) kept under submissive control by a good sheepdog in the form of an authoritatrian ward sister.

Aggression must be accepted, for what it is, namely an attempt to shake off dominance by others in order to reach maturity and recover an adult relationship with people. It must be met with kindness and firmness and reduced in degree by active support. 
Home visits are inestimable at this stage in order to help reintegration with the family (Hohmann, I969).

As soon as they are fit to do so every patient is encouraged to go home at frequent intervals, if, of course, there is a home to go to. Where relatives live reasonably close, that is within a range of 50 miles or so, and can provide transport, the patients go home every weekend from Friday night to Sunday night. Where the distance is greater, leave is granted for three nights every fortnight and where distances are greater still or train or ambulance services are required, the patients have five nights at home every five weeks. If there is no home, or relatives are incapable of accepting responsibility, the position is tragic but fortunately rare.

Failure to mature through the aggressive stage leaves the patient with a chip on his shoulder which may continue as lasting resentment or be sublimated into a fight for better social conditions for the disabled. Success leads to a good or excellent mental adjustment.

\section{STATISTICS}

The paraplegic unit at Edenhall Hospital has 22 male and 6 female beds. It does not have facilities for the treatment of grave initial complications of injury nor has it facilities for long-term care, although a few patients do have to be retained on a long-term basis.

During the ten-year period under discussion, 263 paraplegic or tetraplegic patients were admitted or seen for the first time as out-patients. Of these 82 have been eliminated from this survey either because the onset had been more than two years previously or because the final neurological deficit was minimal.

Of the I8I patients remaining in the survey 92 per cent. were traumatic and 84 per cent. were male.

\section{EFFECT OF AGE}

A study of the case records confirmed an impression we had built up over the years that, on the whole, the young adjust better than the old. Following a more detailed study we have drawn two rather arbitrary lines at age 20 and age 45 (Table I).

The Under 20s. The youngest of these patients was a girl of I4, so all were teenagers. There were in all I8, I7 male and I female, all still survive and in all the mental adjustment was reasonably good.

We have adopted five gradings - failure, poor, fair, good and excellent mental adjustment and in these youngsters the ratings were: Failure, nil; Poor, nil; Fair, 3; Good, 7; Excellent, 8 (Tables II and III).

They have youth on their side. One would think that there would be a high rate of resentment and despair at the loss of physical ability and virility, but while adjustment may be slow in some cases the final results are remarkable.

The Over 45s. Here the pattern is very different. There is much greater resentment at the loss of function, the older ones feel that they are less able to cope and they may feel that they will be an impossible burden for their relatives. Some may be faced with permanent institutionalisation and some just do not try, feeling that they have nothing left to live for. 
TABLE I

Age and Sex Distribution

\begin{tabular}{|c|c|c|c|c|}
\hline Age & $M$ & $\mathrm{~F}$ & Total & Group totals \\
\hline $0-20$ & I7 & I & I8 & I8 \\
\hline $20-30$ & 47 & 3 & 50 & \multirow{3}{*}{97} \\
\hline $30-40$ & 23 & 9 & 32 & \\
\hline $40-45$ & I4 & I & I5 & \\
\hline $45-55$ & 26 & 3 & 29 & \multirow{3}{*}{66} \\
\hline \multirow{3}{*}{ Over 65} & $2 \mathrm{I}$ & 9 & 30 & \\
\hline & 4 & 3 & 7 & \\
\hline & 152 & 29 & $\mathrm{I} 8 \mathrm{I}$ & I $8 \mathrm{I}$ \\
\hline
\end{tabular}

TABLE II

Mental Adjustment Ratings by Age-groups

(Deaths in brackets)

\begin{tabular}{|c|c|c|c|c|c|c|}
\hline Age-group & Failure & Poor & Fair & Good & Excellent & Total \\
\hline I0-20 & - & - & $3(0)$ & $7(0)$ & $8(0)$ & I8 (0) \\
\hline $20-45$ & $6(2)$ & I5 (3) & I7 (-) & $43(2)$ & I6 (I) & $97(8)$ \\
\hline Over 45 & II (8) & $9(6)$ & I9 (6) & 2I (4) & $6(2)$ & $66(26)$ \\
\hline & I7 (I0) & $24(9)$ & $39(6)$ & 7I (6) & $30(3)$ & I8I (34) \\
\hline
\end{tabular}

Table III

As Table II, Condensed

(Deaths in brackets)

\begin{tabular}{|c|c|c|c|}
\hline Age-group & $\begin{array}{c}\text { Failure, poor, } \\
\text { or fair }\end{array}$ & $\begin{array}{c}\text { Good or } \\
\text { excellent }\end{array}$ & Total \\
\hline I0-20 & $3(0)$ & I5 (0) & I8 (0) \\
\hline $20-45$ & $38(5)$ & $59(3)$ & $97(8)$ \\
\hline Over 45 & $39(20)$ & $27(6)$ & $66(26)$ \\
\hline & $80(25)$ & IOI (9) & I8I (34) \\
\hline
\end{tabular}


There were 66 patients in this group, 45 under the age of 60 and 21 over 60 . Fifty-two were males and 15 females and 26 (40 per cent.) are known to have died.

Their mental adjustment ratings were: Failure, I I; Poor, 9; Fair, I9; Good, 2I; and Excellent, 6. It may be significant that the II failures had a slightly higher median age and that 8 of the I I are dead.

Age 20 to 45. In this group other factors, such as differences in personality and home circumstances, seem to be more relevant. Ninety-seven, or just over half of the cases were in this group, 83 being males and I 3 females. Eighty-eight, that is 92 per cent. still survive.

The mental adjustment ratings lay between the other two groups: Failure, 6; Poor, I5; Fair, I7; Good, 43; Excellent, I6.

\section{PREVIOUS PERSONALITY AND PROBLEMS}

In the cases we studied we looked for personality problems and other difficulties apparent in the patient's life prior to accident and compared these with the mental adjustment ratings. The patients were divided into three categories; those with a totally unsatisfactory past life history, due to psychological or environmental causes; those with major problems they had been unable to resolve, such as the imminent break-up of marriage, immaturity or a low I.Q. making life a constant struggle; and finally those whose previous life and social relations appeared to have been satisfactory.

\section{TABLE IV}

Previous Personality and Social Problems Related to Mental Adjustment

\begin{tabular}{|l|c|c|c|c|}
\hline $\begin{array}{c}\text { Mental } \\
\text { adjustment } \\
\text { rating }\end{array}$ & $\begin{array}{c}\text { Unsatisfactory } \\
\text { life } \\
\text { history }\end{array}$ & $\begin{array}{c}\text { Severe } \\
\text { social } \\
\text { problems }\end{array}$ & $\begin{array}{c}\text { Satisfactory } \\
\text { pre-accident }\end{array}$ & Total \\
\hline Failure & $53 \%(8)$ & $18 \%(3)$ & $29 \%(6)$ & I 7 \\
\hline Poor & $33 \%(8)$ & $25 \%(6)$ & $42 \%(10)$ & 24 \\
\hline Fair & $10 \%(4)$ & $26 \%(10)$ & $64 \%(25)$ & 39 \\
\hline Good & $7 \%(5)$ & $19 \%(13)$ & $74 \%(53)$ & 7 I \\
\hline Excellent & - & - & $100 \%(30)$ & 30 \\
\hline & $14 \%(25)$ & $17 \%(32)$ & $69 \%(124)$ & $18 \mathrm{I}$ \\
\hline
\end{tabular}

Correlation with Adjustment Ratings. In the group of failures, taking all ages together, 53 per cent. had an unsatisfactory life history, I8 per cent. had problems and 29 per cent. had led satisfactory lives as far as we were aware (Table IV). 
Of those rated as poor, 33 per cent. had unsatisfactory lives, 25 per cent. had severe problems and 42 per cent. had had satisfactory lives.

Those rated as fair had io per cent. with a totally unsatisfactory previous history, severe problems were endured by 26 per cent. while the satisfactory percentage rose to 64 .

Those rated as good had 7 per cent. with an unsatisfactory history, I 9 per cent. with severe problems and 7I per cent. had had satisfactory lives.

Finally, all 30 patients rated as having made an excellent mental adjustment had had satisfactory lives prior to injury. In most cases these patients came from exceptionally warm and loving backgrounds. It is also obvious that people who managed well enough, so far as can be seen, can collapse under the enormous added strain that paraplegia brings and fail to make a good adjustment.

As mentioned earlier, 8 of the I I failures in the over-45s are now dead and it is of interest that 7 of these 8 had unsatisfactory previous lives or were living with severe and unresolved problems before the onset of their paraplegia.

\section{SOCIAL POSITION}

Good adjustment cuts across social barriers and highly educated people have been found in our poor adjustment ratings. There are, however, more educated people in our highest rating and, in that category, all were people of reasonable intelligence.

Our largest grouping was the second highest, rated as 'good', and in this group there are people of widely differing intelligence, background and education.

It is a grave mistake to think that an articulate educated man does not need skilled help with adjustment problems. It is necessary to look for the problems not expressed that are being deliberately repressed-the deeply emotional issuesrather than to feel that all is well because the patient is talking intelligently about his condition and making practical plans. It is wise to remember that reasoned response comes before the emotional ferment has sorted itself out-sometimes years before. It is also as well to remember that the patient's presenting problem is always a practical one although he is frequently looking for help at a deeper level. The hope of the hospital social worker is that the patient can come face to face with some of these emotional problems before discharge, thus relieving the family of some of the anxiety and protecting the now more tenuous family bond.

We feel that practical problems, particularly housing, finance and transport are important and the hospital staff must help to sort out these difficulties. The patient has many hurdles to overcome and he must be relieved of a little of the burden but decisions must be his and he must be led to face up to difficulties and not expect everything to bo done for him.

\section{RELIGION}

A strongly held feeling of support through religious belief is naturally an added help in getting through the emotional stages leading to re-identification but when belief becomes delusion this can lead to failure, as with one of the patients among our own series who is still lying in bed, at home, waiting for the miracle that he is still convinced will occur enabling him to pick up his bed and walk. 


\section{SEXUALITY}

As Talbot (I969) has recently pointed out, there are two sides to sexualitythe psychic and the physical. For many years the subject was taboo but gradually there has developed a more open discussion with the patient of the physical possibilities. This will help those who have a chance of some degree of genital sex but glosses over the problems of those whose chances are poor or absent, or for whom the only physical sex possible will be clumsy and very different from their previous experience.

Even if you take partial sex function from a man he still tends to feel that he has lost his manhood. We all know of patients of either sex who, while still in hospital, have a desperate need to prove their attraction to the opposite sex, trying to make as many conquests as they can in order to assure themselves that they have not changed in this respect. This trait is perhaps more noticeable when we are dealing with female patients-in the male it is looked on as more normal!

We note that those patients who overcome their altered sex role best tend to be married men who have several children-a proof, as it were, of their one-time virility. The adolescent, on the other hand is still experimenting and can continue to do so with the help of fantasy.

Where physical sexual experience is no longer possible or when it diminishes, as so often happens, the psychological element continues-the impotent paraplegic is neither a eunuch nor is he mindless-and it may be compensated and sublimated by creative work.

Marriages which take place after injury are usually secure (Bors, I963) because the contract has not, as it were, been broken. We agree, with this with one proviso, that is that couples engaged at the time of injury and subsequently marrying do tend to have some difficulty. We do not have sufficient figures to draw definite conclusions but our experience is such that we keep a wary eye on these cases.

\section{CLINICAL PROBLEMS}

The level of lesion would appear to be relatively unimportant. Many tetraplegics made an excellent or good mental adjustment while some cauda equina lesions were rated as poor.

Delays in rehabilitation due to skin or bladder problems have their effect on the speed of mental adjustment but have little influence on the final outcome. We feel also that in patients who return again and again with major psychological problems and severe pressure sores, the clinical problem is more often secondary to the psychological one, including a low I.Q. rather than the other way round. Thompson and Murray (1967), however, in their follow-up of patients in their own homes, did find one or two patients for whom life had been made miserable by persistent urological problems. Severe pain, whether 'root' pain, 'visceral' pain or 'phantom' pain, can only be measured subjectively. The part played by poor mental adjustment in adding a psychogenic factor requires further investigation (Wright \& Sweet, I969).

\section{DESIRE TO WORK}

Immediately after injury a patient expresses a strong desire to return to work and, as we have mentioned previously, this is really an expression of his desire to return to his accustomed place in society. 
During mental adjustment the majority of patients must learn to accept the fact that they will not be able to return to their previous employment and they then have to face the problem of whether they should seek alternative work or some other form of fulfilment. Some who will never be able to work again adapt to their new life extraordinarily well while in those who are fit for work the desire will be influenced by the degree of mental adjustment, financial security and many other factors.

We feel that a satisfactory return to work of some kind is more likely to be the result of a good adjustment rather than a factor in achieving it.

\section{FINANCIAL SECURITY}

There is no doubt, on the other hand, that financial security is a major factor in adjustment. Of all the 30 cases rated as excellent there was only one where financial hardship might have been a problem and even that patient was well cushioned by many generous and protective relatives from a large close-knit family group.

\section{CONCLUSION}

Paraplegia is there for life and one only sees the beginning stages in hospital. We feel that it takes at least two years for the average patient to stabilise and during this period he needs all the help he can get while making the necessary mental adjustment. It is here that one sees to its best advantage the relatively small unit where everyone knows everyone and there is good continuity of staff and care and good follow-up. As the patients have all virtually suffered the same disability they can also be of tremendous help to each other as long as the morale of the unit is high (Hohmann, I969).

A new problem looming ahead is the absorption of spina bifida patients into this community when they reach adolescence and leave the care of paediatric units. We are well aware of this problem in Edinburgh and are actively exploring ways of meeting it. Lister (I97I) has been impressed with the change for the better in these teenagers when they get amongst grown-ups but the process is a little traumatic and he feels, like we do in Edinburgh, that there is a need for a bridging adolescent unit where care can gradually be transferred.

In conclusion we wish to stress that the major factors in good mental adjustment are the patient's previous mental and family background and his age. As Naughton (I963) stressed, 'The human race is remarkably tough and adaptable in the face of real adversity and, within limits, is stimulated by it'. We must do all we can to help this process.

\section{SUMMARY}

A study has been made of the acceptance of disability by I8I patients treated at Edenhall Hospital during the ten years from I.I.6I to 3I.I2.70.

Their mental adjustment has been graded as failure, poor, fair, good or excellent and the factors influencing adjustment have been explored.

The most important factors in achieving a good adjustment are the previous background of the patient, both personal and environmental, and the patient's age. The young were found to have adjusted very much better than the old. 
Other factors, such as education, desire to work and clinical problems are also discussed.

It is concluded that the adjustment process takes two years at least to complete and that it can best be helped in the atmosphere of a small unit where the patients have similar disabilities and problems and where the morale is high.

\section{REFERENCES}

Bors, E. (1963). Personal communication.

FoRMAN, J. A. S. (197I). British Medical fournal, 2, 706.

HohmanN, G. W. (I969). Proceedings of the I7th Veterans Administration Spinal Cord Injury Conference, 224.

Lister, J. (I97I). Personal communication.

Naughton, J. A. L. (1963). Proceedings of a Symposium on Spinal Injuries, Ed. by P. Harris, Royal College of Surgeons, Edinburgh, 137.

StorR, A. (1960). The Integrity of the Personality. London: Wm. Heinemann.

TALBOT, H. S. (1969). Proceedings of the I7th Veterans Administration Spinal Cord Injury Conference, 222.

Thompson, M. A. \& Murray, W. A. (1967). Paraplegia at Home, 15. Edinburgh: E. \& S. Livingstone.

Walsh, J. J. (1964). Understanding Paraplegia. London: Tavistock Publications.

WRIGHT, R. L. \& SWEeT, W. H. (1969). Proceedings of the I7th Veterans Administration Spinal Cord Injuries Conference, 77. 